\title{
sciendo
}

\section{USE OF NOVEL METHODS TO ASSESS SEASONAL DIFFERENCES IN THE QUALITY OF BOAR SEMEN STORED UP TO 7 DAYS AT $17^{\circ} \mathrm{C}$ *}

\author{
Barbara Szczęśniak-Fabiańczyk ${ }^{1 \star}$, Michał Bochenek², Piotr Gogol ${ }^{1}$, Monika Trzcińska ${ }^{1}$, Magdalena \\ Bryła $^{1}$, Zdzisław Smorąg $^{1}$

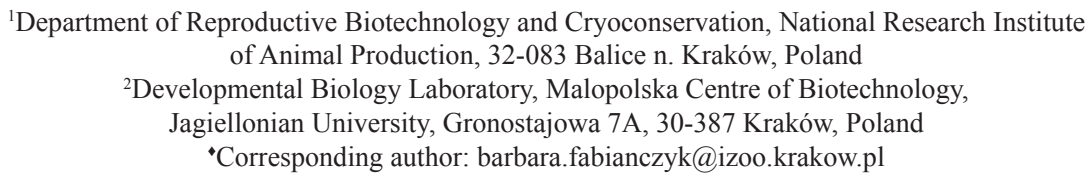

\begin{abstract}
The objective of the present study was to determine the seasonal changes in boar semen quality by the assessment of sperm membrane integrity, analysis of chromatin structure, assessment of oxidative stress and of apoptotic changes in spermatozoa. Semen from 16 boars (172 ejaculates) was investigated. The males were aged between 7 months and 7 years. Semen was extended with BTS diluent and stored at $+17^{\circ} \mathrm{C}$. During seven days of storage, the semen was subjected to standard evaluation and novel methods for semen assessment. In the autumn-winter period, the semen had higher evaluations than in the spring-summer period, but only sperm membrane integrity examination showed significantly lower $(\mathrm{P} \leq \mathbf{0 . 0 1})$ percentage of moribund spermatozoa and the semen had a significantly $(\mathrm{P} \leq \mathbf{0 . 0 5})$ lower (by $0.5 \%$ ) percentage of sperm with damaged chromatin. Examination performed after 7-day storage showed significantly $(P \leq 0.01)$ higher percentage of live spermatozoa and with high mitochondrial membrane potential for the autumn-winter period. The level of apoptotic cells was significantly $(\mathrm{P} \leq \mathbf{0 . 0 1})$ lower for the autumn-winter period. Examination of sperm membrane integrity after 7 days of storage showed a lower $(\mathrm{P} \leq 0.05)$ percentage of moribund spermatozoa for the autumn-winter period. In our opinion, novel methods for sperm assessment may be used to monitor new parameters of sperm function.
\end{abstract}

Key words: boar semen, membrane integrity, chromatin structure, oxidative stress, apoptotic changes

The quality of collected semen is a significant factor in artificial insemination (fertility) results. The quantitative and qualitative parameters of fresh boar semen

\footnotetext{
*This work was conducted as part of the research project "The uses and the conservation of farm animal genetic resources under sustainable development" co-financed by the National Centre for Research and Development within the framework of the strategic R\&D programme "Environment, agriculture and forestry" - BIOSTRATEG, contract number: BIOSTRATEG2/297267/14/NCBR/2016.
} 
are dependent on genetic factors such as breed (Knecht et al., 2014), age of boar (Tsakmakidis et al., 2012) and broader environmental conditions (including feeding, animal welfare, air temperature and humidity) (Smital, 2010; Knox, 2016).

It is widely accepted that high ambient temperature adversely affects semen quality in boars (Rodriguez et al., 2017; Peňa et al., 2018). This view is based on several-year observations of physical characteristics of semen such as ejaculate volume, sperm concentration and the resulting number of spermatozoa per ejaculate (Reed, 1986; Smital, 2009; Adamiak et al., 2010; Knecht et al., 2014; Górski et al., 2017). In the summer, when temperatures are at their highest, ejaculates are characterised by lower volume and lower sperm count in the ejaculate (Kondracki et al., 2004; Wysokińska et al., 2008; Smital, 2009; Adamiak et al., 2010). Seasonal differences in semen motility and in morphological status of spermatozoa were also observed (Kennedy and Wilkins, 1984; Reed, 1986; Górski et al., 2017). Highest sperm motility was found in late autumn (Wysokińska et al., 2008) or in spring and summer (Górski et al., 2017), and a higher percentage of morphologically normal spermatozoa between November and April (Banaszewska et al., 2007). Taking the total number of live spermatozoa per ejaculate as the outcome of volume, concentration and motility, spring and autumn (Szostak, 2003) or autumn and winter (Smital et al., 2004; Knecht et al., 2014) were considered the most favourable periods for semen production by the boars. Based on analysis of data from insemination stations, Sonderman and Luebbe (2008) concluded that between June and October, considerably more ejaculates are discarded due to poor quality.

The standard semen evaluation determines ejaculate volume and sperm motility and concentration, and also includes periodic morphological evaluation (Banaszewska et al., 2007; Kennedy and Wilkins, 1984; Szostak, 2003). Occasionally it is extended to include biochemical tests or assessment of the sperm membrane for damage or osmotic capacity. New possibilities for cell assessment have emerged in recent years, including the application of flow cytometry (Gillan et al., 2005) and measurement of bioluminescence (Gogol et al., 2007; Gogol et al., 2009).

The objective of the present study was to determine the expected seasonal changes in boar semen quality by the above-mentioned cell parameters and methods.

\section{Material and methods}

Semen from 16 boars (5 Polish Large White, 4 Polish Landrace, 1 English Large White, 1 Austrian Landrace, 5 Pietrain $\times$ Duroc hybrid boars) was investigated. The boars were raised under the same conditions at the Experimental Station of the National Research Institute of Animal Production in Żerniki Wielkie Ltd. Males were aged between 7 months and 7 years. Semen for analysis was collected at monthly intervals for 2.5 years. A total of 172 manually collected ejaculates were studied.

After collection and removal of the gel fraction, the semen was evaluated for ejaculate volume, sperm concentration (spectrometer) and motility, and then extended with BTS diluent (Minitüb, Germany) to give $2.5 \times 10^{9}$ motile sperm per semen 
dose $(90 \mathrm{ml})$ and preparations for morphological assessment were made. The diluted semen was placed in tubes and stored at $+17^{\circ} \mathrm{C}$. During seven days of storage, the semen was subjected to standard evaluation for motility and morphology and evaluated using novel methods.

\section{Standard evaluation}

It covered the assessment of motility and morphological evaluation.

\section{Assessment of motility}

To evaluate motility of the preserved semen, $1 \mathrm{ml}$ samples were collected from the stored insemination doses and placed in a water bath at $37^{\circ} \mathrm{C}$. After $30 \mathrm{~min}$-incubation, the semen was assessed by two experienced observers under a Nikon optical phase-contrast microscope (magnification $100 \times$ ) with a heating table. Motility assessment was performed until sperm motility dropped below 30\%. This served as a basis for determining sperm survival time, or the number of days during which at least $30 \%$ motile spermatozoa were observed.

\section{Morphological assessment}

Preparations for morphological assessment were made from fresh semen immediately after dilution, fixed, stained with Giemsa (Sigma-Aldrich) and evaluated for at least 200 spermatozoa at $1000 \times$ magnification. The assessment was based on Blom's classification (Blom, 1981), which provided a basis for classifying the spermatozoa into three groups: normal (without morphological defects), with primary defects and with secondary defects.

\section{Examination with novel methods}

It covered the assessment of sperm membrane integrity, sperm chromatin structure, oxidative stress and apoptotic changes.

\section{Assessment of sperm membrane integrity}

Sperm membrane integrity was examined with a flow cytometer (CytoFLEX, Beckman Coulter) using double staining with the fluorochromes SYBR-14 and propidium iodide (PI). The examination was performed twice: after 1 and $7 \mathrm{~d}$ of storage. Prior to staining, the semen was diluted to $20 \times 10^{6} \mathrm{sperm} / \mathrm{ml}$ with PBS. Next, $10 \mu \mathrm{l}$ of SYBR-14 stock solution was added to $1 \mathrm{ml}$ of semen and incubated at $+35^{\circ} \mathrm{C}$ for $10 \mathrm{~min}$, after which $10 \mu \mathrm{l}$ of PI stock solution was added (Live/Dead Sperm Viability Kit, Molecular Probes). Analysis was started after the next 10 min of incubation at room temperature. Double staining allowed the spermatozoa to be divided into three groups: sperm with intact cell membrane ("live"), metabolically active sperm with damaged cell membrane ("moribund"), and metabolically inactive sperm with damaged cell membrane ("dead").

\section{Assessment of chromatin structure}

Sperm chromatin structure was assessed using the Sperm Chromatin Structure Assay (Evenson et al., 2002). The analysis was performed after 7 days of semen stor- 
age at $+17^{\circ} \mathrm{C}$. Prior to analysis, the semen was diluted to $1 \times 10^{6} \mathrm{sperm} / \mathrm{ml}$ with PBS. Thereafter, 1.0 $\mathrm{M}$ of $\mathrm{HCl}$ solution was used to decrease the sample's $\mathrm{pH}$ to around 1.3 (for partial denaturation of the chromatin) for $30 \mathrm{sec}$. Then acridine orange (AO) was added, and after 3 min incubation at $+4^{\circ} \mathrm{C}$, green fluorescence (normal DNA) and red fluorescence (fragmented DNA) were measured by flow cytometry. DNA Fragmentation Index (DFI - percentage of spermatozoa with fragmented DNA) was determined for each ejaculate.

\section{Assessment of oxidative stress}

Sperm damage due to high oxidative stress was assessed based on induced luminescence of spermatozoa, which was measured after 1 and 7 days of semen storage. Luminescence was measured using an AutoLumat LB953 luminometer (Berthold) as described by Gogol and Szczęśniak-Fabiańczyk (2006). The light emission kinetics was measured during $600 \mathrm{sec}$ at $+20^{\circ} \mathrm{C}$. The following luminescence parameters were calculated: Integral - total integral of the measurement signals, and Peak max $_{-}$ maximal height of the peak.

\section{Assessment of apoptotic changes}

Apoptotic changes were assessed after 1 and $7 \mathrm{~d}$ of semen storage at $+17^{\circ} \mathrm{C}$. Two evaluation methods were used:

- the level of transmembrane mitochondrial potential $(\Delta \mathrm{Y})$ of spermatozoa was measured with the dye JC-1 (5,5',6,6'-tetrachloro-1,1',3,3'tetraethylbenzimidazolyl carbocyanine iodide/chloride) (Molecular Probes Inc., Eugene, USA). Samples containing $1 \times 10^{6}$ spermatozoa were washed with $2 \mathrm{ml} \mathrm{PBS}$ without $\mathrm{Ca}$ and $\mathrm{Mg}$ ions, and centrifuged at $300 \mathrm{~g}$ for $10 \mathrm{~min}$. After collection of the supernatant, the spermatozoa were placed in PBS solution (about $1 \mathrm{ml}$ ) containing $10 \mu \mathrm{l}$ of fluorochrome JC- 1 . Incubation was conducted at $37^{\circ} \mathrm{C}$ for $15 \mathrm{~min}$ (Trzcińska et al., 2008; Trzcińska and Bryła, 2015),

- changes in sperm membrane permeability were identified based on apoptosischaracteristic micropores in the external cytoplasmic membrane, using fluorochrome YO-PRO-1 (Vybrant Apoptosis Assay Kit\#4, Molecular Probes, USA). Samples containing $1 \times 10^{6}$ spermatozoa were rinsed with $2 \mathrm{ml} \mathrm{PBS}$, and centrifuged at $300 \mathrm{~g}$ for $10 \mathrm{~min}$. After collection of the supernatant, the spermatozoa were placed in PBS solution containing $2 \mu \mathrm{l}$ of YO-PRO-1 and $1 \mu \mathrm{l}$ of propidium iodide (PI). Incubation was performed in darkness at room temperature for $20 \mathrm{~min}$.

Individual subpopulations of spermatozoa (200 spermatozoa per sample) were observed under a fluorescence microscope (Nikon Eclipse E600, Tokyo, Japan) using the following filters:

- a $520 \pm 20 \mathrm{~nm}$ filter - green fluorescence of apoptotic cells stained with the fluorochrome YO-PRO-1; green fluorescence of sperm with low mitochondrial membrane potential (low $\Delta \mathrm{Y}$ ); red-orange fluorescence of sperm with high mitochondrial membrane potential (high $\Delta \mathrm{Y}$ ) stained with JC-1,

$-\mathrm{a}>620 \mathrm{~nm}$ filter - red fluorescence of necrotic cells stained with propidium iodide. 


\section{Statistical analysis}

The values in the tables were determined by calculating the mean (x) and standard error (SE). In the statistical calculations, variance analysis was performed with SAS software (General Linear Models Procedure). The data were analysed according to the following model:

$$
Y_{i j}=m+a_{i}+e_{i j}
$$

where:

$Y_{i j}$ - trait level,

$m$ - population mean,

$a_{i}-$ effect of season,

$e_{i j}$ - error.

The significance of differences was tested by Duncan's Multiple Range Test for variable. The calculations accounted for two seasons of the year: spring-summer, from early April to late September; and autumn-winter, from early October to late March. The significance of differences between the level of sperm parameters measured on $\mathrm{d} 1$ and 7 of storage for autumn-winter and spring-summer periods was tested by $\mathrm{T}$ test.

\section{Results}

The 172 ejaculates used in the present study had a mean volume of $238.3( \pm 6.7)$ $\mathrm{ml}$ and concentration of $384.4( \pm 9.0) \times 10^{6}$ spermatozoa $/ \mathrm{mm}^{3}$, of which 55 ejaculates came from 5 Polish Large White boars (mean volume of $226.7( \pm 9.6) \mathrm{ml}$ and concentration of $376.1( \pm 13.8) \times 10^{6}$ spermatozoa $\left./ \mathrm{mm}^{3}\right), 45$ ejaculates from 4 Polish Landrace boars (mean volume of $291.6( \pm 17.9) \mathrm{ml}$ and concentration of 350.2 $( \pm 19.1) \times 10^{6}$ spermatozoa $\left./ \mathrm{mm}^{3}\right), 7$ ejaculates from 1 English Large White boar (mean volume of $172.9( \pm 13.7) \mathrm{ml}$ and concentration of $455.7( \pm 33.8) \times 10^{6}$ spermatozoa $/ \mathrm{mm}^{3}$ ), 6 ejaculates from 1 Austrian Landrace boar (mean volume of 268.3 $( \pm 19.2) \mathrm{ml}$ and concentration of $\left.274.5( \pm 42.4) \times 10^{6} \mathrm{spermatozoa} / \mathrm{mm}^{3}\right)$, and 59 ejaculates from 5 Pietrain $\times$ Duroc hybrid boars (mean volume of $213.1( \pm 7.5) \mathrm{ml}$ and concentration of $414.9( \pm 15.2) \times 10^{6}$ spermatozoa $\left./ \mathrm{mm}^{3}\right)$.

In the spring-summer half-year, 94 ejaculates with a mean volume of 237.0 $( \pm 9.1) \mathrm{ml}$ and concentration of $380.7( \pm 11.8) \times 10^{6}$ spermatozoa $/ \mathrm{mm}^{3}$ were collected compared to 78 ejaculates with a volume of $239.8( \pm 10.0) \mathrm{ml}$ and concentration of $388.8( \pm 13.9) \times 10^{6}$ spermatozoa $/ \mathrm{mm}^{3}$ in the autumn-winter half-year. These differences were not significant.

The results of boar semen evaluation in both half-years, performed after oneday storage, and the results of the morphological assessment of the fresh semen are presented in Table 1. In the autumn-winter period, the semen had higher evaluations than in the spring-summer period, namely higher motility (by $5.2 \%$ on average, non- 
significant) and higher percentage of morphologically normal spermatozoa (by $1.8 \%$ on average, non-significant).

Sperm membrane integrity examination showed a non-significant higher percentage of spermatozoa with intact cell membranes (by $4.6 \%$ on average) but a significantly lower $(\mathrm{P} \leq 0.01)$ percentage of moribund spermatozoa.

Apoptosis examination showed a higher level of live spermatozoa for YOPRO-1/PI by $4.4 \%$ on average (non-significant) and a higher level of spermatozoa with intact mitochondrial function for $\mathrm{JC}-1$ by $4.4 \%$ on average (non-significant).

The ejaculates collected in the autumn-winter period exhibited lower but nonsignificant level of oxidative stress.

In the evaluation of survival time made during storage, the semen collected between early October and late March was observed to retain over 30\% motility for an average of 1.3 more days compared to the semen collected between early April and late September. However, the differences were not significant.

Table 1. Seasonal changes in boar semen quality after one-day storage and morphological assessment depending on season of the year

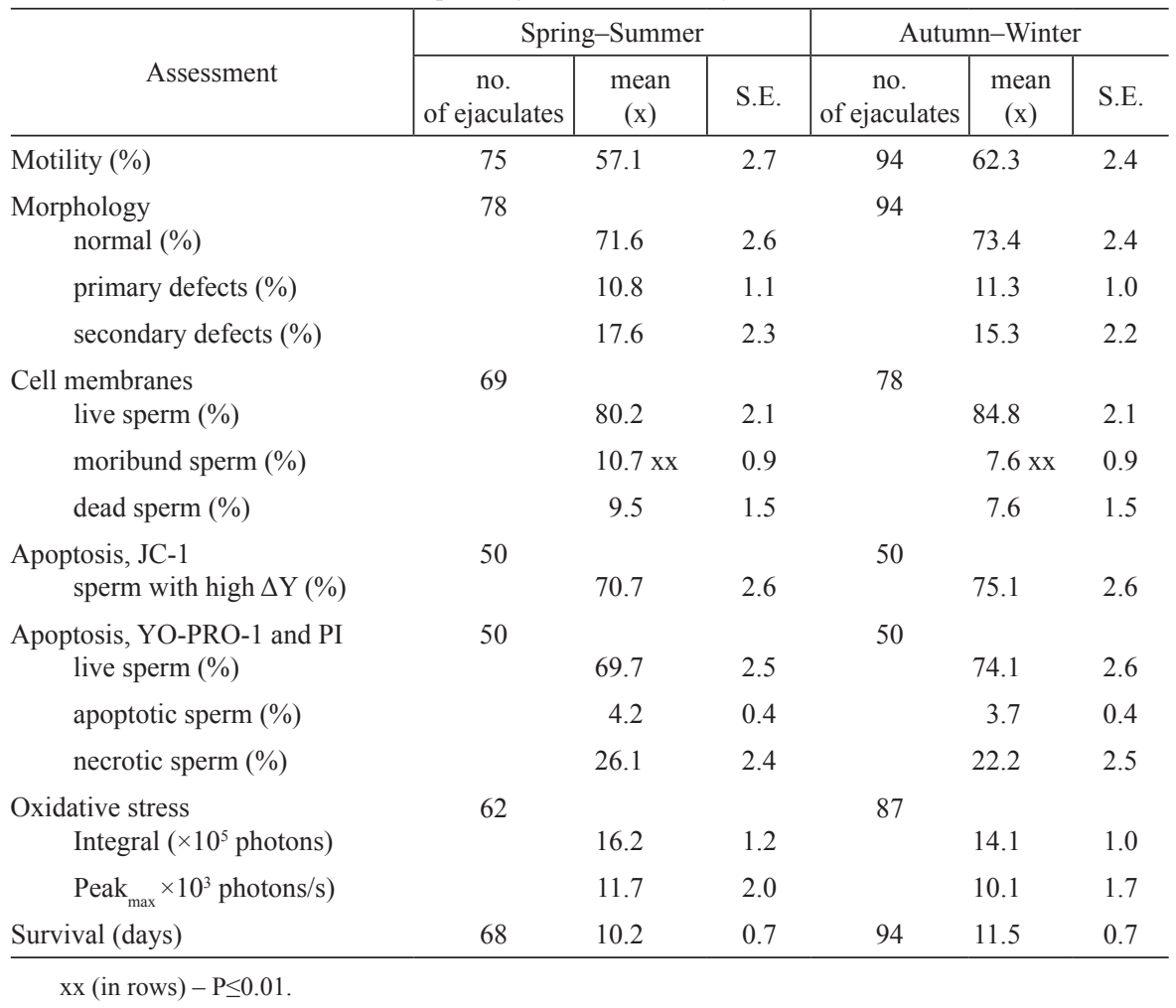

The assessment of motility, cell membrane integrity, oxidative stress, apoptotic changes and chromatin structure performed after $7 \mathrm{~d}$ of semen storage at $+17^{\circ} \mathrm{C}$ is presented in Table 2. 
Table 2. Seasonal changes in boar semen quality after $7 \mathrm{~d}$ of storage at $+17^{\circ} \mathrm{C}$

\begin{tabular}{|c|c|c|c|c|c|c|}
\hline \multirow[b]{2}{*}{ Assessment } & \multicolumn{3}{|c|}{ Spring-Summer } & \multicolumn{3}{|c|}{ Autumn-Winter } \\
\hline & $\begin{array}{c}\text { no. } \\
\text { of ejaculates }\end{array}$ & $\begin{array}{c}\text { mean } \\
(\mathrm{x})\end{array}$ & S.E. & $\begin{array}{c}\text { no. } \\
\text { of ejaculates }\end{array}$ & $\begin{array}{c}\text { mean } \\
(\mathrm{x})\end{array}$ & S.E. \\
\hline Motility (\%) & 68 & 45.5 & 2.6 & 94 & 51.7 & 2.5 \\
\hline Cell membranes & 69 & & & 78 & & \\
\hline live sperm $(\%)$ & & 75.3 & 2.1 & & 81.5 & 2.1 \\
\hline moribund sperm (\%) & & $12.8 \mathrm{x}$ & 1.1 & & $9.4 \mathrm{x}$ & 1.1 \\
\hline dead sperm $(\%)$ & & 11.9 & 1.5 & & 9.1 & 1.5 \\
\hline $\begin{array}{l}\text { Apoptosis, JC-1 } \\
\text { sperm with high } \Delta \mathrm{Y}(\%)\end{array}$ & 50 & $53.3 \mathrm{xx}$ & 2.6 & 50 & $63.3 \mathrm{xx}$ & 2.4 \\
\hline $\begin{array}{c}\text { Apoptosis, YO-PRO-1 and PI } \\
\text { live sperm }(\%)\end{array}$ & 50 & $49.2 \mathrm{xx}$ & 2.7 & 50 & $59.2 \mathrm{xx}$ & 2.8 \\
\hline apoptotic sperm (\%) & & $5.7 \mathrm{xx}$ & 0.6 & & $3.1 \mathrm{xx}$ & 0.4 \\
\hline necrotic sperm (\%) & & 45.1 & 2.7 & & 37.7 & 2.8 \\
\hline $\begin{array}{l}\text { Oxidative stress } \\
\text { Integral }\left(\times 10^{5} \text { photons }\right)\end{array}$ & 62 & 24.1 & 1.7 & 87 & 20.4 & 1.5 \\
\hline Peak $_{\max }\left(\times 10^{3}\right.$ photons $\left./ \mathrm{s}\right)$ & & 20.6 & 3.4 & & 18.2 & 3.1 \\
\hline $\begin{array}{c}\text { Chromatin structure } \\
\text { DFI }(\%)\end{array}$ & 80 & $2.8 \times$ & 0.1 & 62 & $2.3 \times$ & 0.2 \\
\hline
\end{tabular}

$\mathrm{xx}$ (in rows) $-\mathrm{P} \leq 0.01$.

$\mathrm{x}$ (in rows) $-\mathrm{P} \leq 0.05$.

Examination performed after 7-d storage showed significantly higher (by $10.0 \%$ on average, $\mathrm{P} \leq 0.01$ ) percentage of sperm with intact mitochondrial function (JC-1 test) for the autumn-winter period. Identical results for live spermatozoa (by $10.0 \%$ on average, $\mathrm{P} \leq 0.01$ ) were found for YO-PRO-1/PI test. The level of apoptotic cells was significantly lower (by $2.6 \%, \mathrm{P} \leq 0.01$ ) in this test for the autumn-winter period.

Examination of sperm membrane integrity after 7-d storage showed the lower percentage of moribund (membrane-damaged, but metabolically still active) spermatozoa (by $3.4 \%$ on average) for the autumn-winter period. This difference was statistically significant $(\mathrm{P} \leq 0.05)$.

The semen obtained during the autumn-winter period had a significantly $(\mathrm{P} \leq 0.05)$ lower (by $0.5 \%$ ) percentage of sperm with damaged chromatin.

There were no statistically significant differences in the level of oxidative stress between the autumn-winter and spring-summer periods.

The boar semen collected during the autumn-winter period was characterised by a slower drop in semen quality (smaller differences between the evaluation results obtained after 1 and $7 \mathrm{~d}$ of storage) compared to the semen collected during the spring-summer period (Figure 1). During 7-d storage of the semen collected between autumn and winter, there was a lower decline in the percentage of motile spermatozoa (by $1 \%$ on average) and those with intact cell membrane (by $1.6 \%$ on average), a significantly $(\mathrm{P} \leq 0.05)$ lower decrease in the percentage of spermatozoa with intact mitochondrial function (JC-1 test - by $5.6 \%$ on average) and without apoptotic 
changes (YO-PRO-1/PI test - by $5.6 \%$ on average) compared to the storage of semen collected between early April and late September. In turn, during the spring-summer period there was a more distinct increase in the percentage of necrotic spermatozoa detected by YO-PRO-1/PI test (by $4.5 \%$ on average) compared to the autumn-winter period. The evaluation of apoptotic changes based on the YO-PRO-1/PI test showed the percentage of apoptotic spermatozoa to decrease in the autumn-winter period (by $0.6 \%$ on average) during the 7 - $\mathrm{d}$ storage, and to increase in the spring-summer period (by $1.5 \%$ on average). The difference was significant $(\mathrm{P} \leq 0.01)$. In spring-summer there was also a higher increase in the percentage of sperm with damaged membranes, both "dead" (by $0.9 \%$ on average) and "moribund" (by $0.3 \%$ on average), and also in the oxidative stress level (Integral - by an average of $1.6 \times 10^{5}$ photon counts; Peak $_{\max }$ - by an average of $0.8 \times 10^{3}$ counts/s) compared to the autumn-winter period.

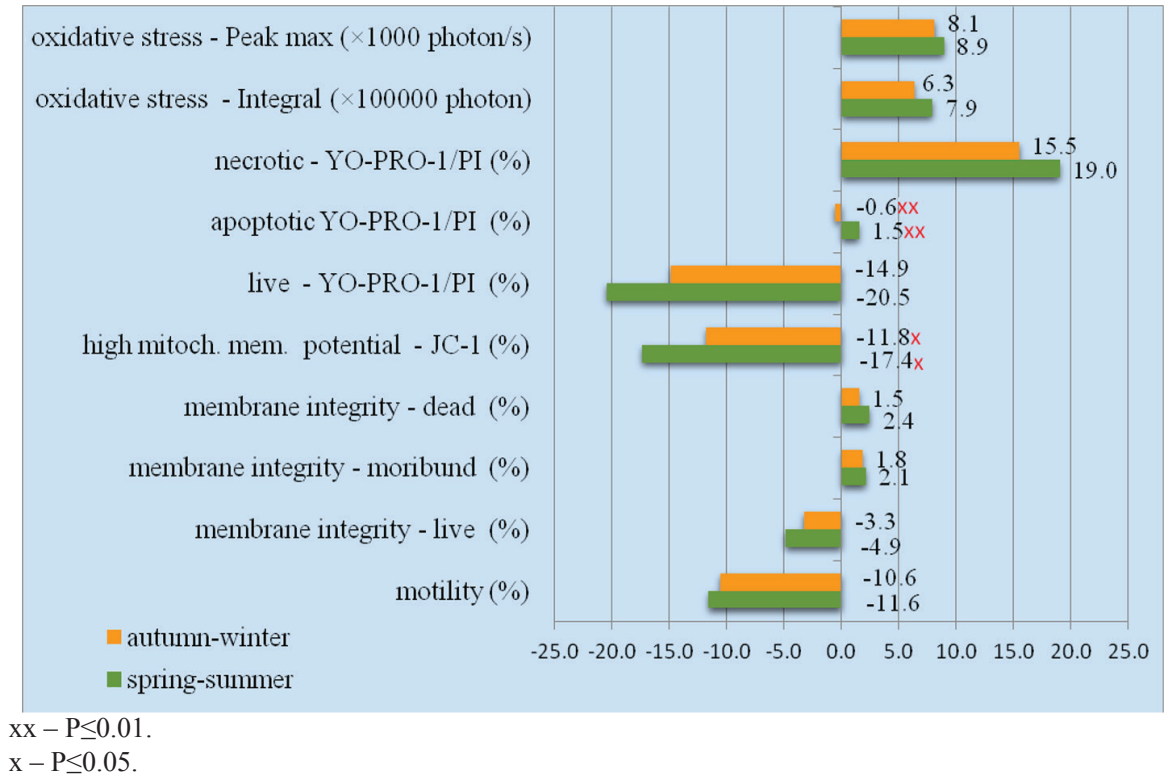

Figure 1. Changes in the level of the examined sperm parameters measured on $\mathrm{d} 1$ and 7 of storage for the autumn-winter and spring-summer periods

\section{Discussion}

The results obtained in our study for the standard evaluation of semen support the observations of other researchers. We obtained higher quality for boar semen collected in the autumn-winter period compared to the spring-summer period. Accordingly, as in the study by Wysokińska et al. (2008), semen collected in the months between October and March had a higher percentage of motile spermatozoa and, similar to the study of Banaszewska et al. (2007), it had a lower percentage of sperm with morphological changes compared to the semen collected between April and September. 
These observations are also confirmed by analysis of the semen data recorded at A.I. centers (Adamiak et al., 2010; Smital et al., 2004).

In the context of the data concerning the quality of semen evaluated with the standard method, it is interesting to note the parameters of spermatozoa evaluated using the novel methods for semen assessment: sperm membrane integrity, analysis of chromatin structure, oxidative stress and apoptotic changes in spermatozoa. Accordingly, in the semen collected in the autumn-winter months, there was a higher percentage of spermatozoa with intact cell membrane as well as a higher percentage of live sperm without apoptotic changes, compared to the semen harvested in the spring-summer months. During the autumn-winter period, the authors also observed a lower level of oxidative stress than in the spring-summer period. However, the differences were not significant. The season of the year had a statistically significant effect on chromatin structure stability and cell membrane integrity. During the springsummer period, DFI was $0.5 \%$ higher $(\mathrm{P} \leq 0.05)$ and there was a $3.1 \%(\mathrm{P} \leq 0.01)$ higher percentage of spermatozoa that had damaged cell membrane, but were metabolically still active ("moribund").

In our study, we also observed the effect of the season on most of the boar semen quality parameters evaluated during its storage at $+17^{\circ} \mathrm{C}$. In the examination of motility and membrane integrity, both the decrease of percentage during storage was small and the differences between the autumn-winter and spring-summer periods were not significant. Considering apoptosis examination, the percentage of live (non-apoptotic) sperms and with intact mitochondrial function decreased considerably during storage, especially in the ejaculates collected in spring-summer and in the assessment made after $7 \mathrm{~d}$ of storage, season had a significant effect on development of apoptotic changes in the spermatozoa. These results confirm the earlier research of Trzcińska et al. (2008), in which the percentage of live sperm significantly decreased, and the percentage of both apoptotic and necrotic spermatozoa increased with extended storage time. It should also be highlighted that for the autumn-winter collected semen, the survival of spermatozoa was over $1 \mathrm{~d}$ longer compared to the spring-summer months.

In the majority of published studies, the percentage of spermatozoa with intact cell membrane, regardless of the method used, remained high $(>90 \%)$ during the first $4 \mathrm{~d}$ of storage (De Ambrogi et al., 2006), over 70\% until d 6, and decreased to 55\% only after $12 \mathrm{~d}$ of storage (Dubé et al., 2004). Boe-Hansen et al. (2008) reported that the percentage of sperm with intact membrane, in semen stored for $3 \mathrm{~d}$, decreased by only $1.1 \%$. In our study, during $7 \mathrm{~d}$ of storage, the percentage of sperm with intact cell membrane decreased by $3 \%$ to almost $5 \%$. In the study by Cerolini et al. (2000), the percentage of spermatozoa with intact membrane decreased significantly from d 2 of storage, and was almost $20 \%$ lower after 4 d, and in the study by Kumaresan et al. (2009) it decreased by almost $46 \%$ during $4 \mathrm{~d}$.

We performed the analysis of chromatin structure only after $7 \mathrm{~d}$ of storage, because in earlier studies (Szczęśniak-Fabiańczyk et al., 2003, 2007; Bochenek, unpublished data) we did not observe DFI to increase in boar spermatozoa stored in a commercial extender for as long as two weeks. Moreover, studies on changes in DNA fragmentation during 21-d storage of boar semen (Pérez-Llano et al., 2006), 
a comparison of different extenders (De Ambrogi et al., 2006), and the relationship of boar fertility with semen storage time and sperm chromatin damage (Waberski et al., 2011) revealed no significant increases in the percentage of spermatozoa with damaged chromatin during storage time of semen. An increase of DFI in the semen stored for $3 \mathrm{~d}$ was only reported by Boe-Hansen et al. (2008).

In regular practice pigs are inseminated mainly with semen stored at above-zero temperatures due to the relatively low efficiency of insemination with frozen semen. Therefore, studies concerning boar semen storage concentrate on the development of liquid and cryopreservation. Rapid and reliable laboratory tests are needed to evaluate the effectiveness of the work done. We believe that the new criteria that we have used, in addition to the standard evaluation to assess sperm parameters such as sperm membrane integrity, chromatin structure, damage due to oxidative stress, mitochondrial functionality and apoptotic changes, address these expectations because they can provide important information concerning the analysed spermatozoa. In our study, novel methods were used to observe semen quality changes determined by the season, and also to assess the quality of stored semen.

The question arises as to the importance of the above parameters of semen quality evaluation in the context of its fertilising capacity. It appears that these parameters may be important from the viewpoint of the biological value of sperm cells.

\section{References}

A d a m i a k A., K on d r a c k i S., Wy s o k iń s k a A. (2010). Influence of season of the year on physical properties of ejaculates from Polish Large White and Polish Landrace boars (in Polish). Rocz. Nauk. Zoot., 37: 159-167.

B anaszewska D., Kondracki S., Wys okińska A. (2007). The influence of the season on the sperm morphology young boars used for insemination (in Polish). Acta Sci. Pol., Zoot., 6: 3-14.

B 1 o m E. (1981). Morphological evaluation of bull spermatozoa. II. Proposition of a new classification of spermatozoa abnormalities (in Polish). Med. Weter., 37: 239-242.

Boe-Hansen G.B., Christensen P., Vibjerg D., Nielsen M.B.F., Hedeboe A.M. (2008). Sperm chromatin structure integrity in liquid stored boar semen and its relationships with field fertility. Theriogenology, 69: 728-736.

Cerolini S., Mald ji an A., S u ra i P., Noble R. (2000). Viability, susceptibility to peroxidation and fatty acid composition of boar semen during liquid storage. Anim. Reprod. Sci., 58: 99-111.

De Ambrogi M., Ballester J., Saravia F., Caballero I., Johannisson A., Wa11gren M., Anders son M., Rodrigues-Martinez H. (2006). Effect of storage in shortand long-term commercial semen extenders on the motility, plasma membrane and chromatin integrity of boar spermatozoa. Int. J. Androl., 29: 543-552.

Dubé C., B e a u li eu M., R e ye s-Moren o C., Guille me t t e C., B a iley J.L. (2004). Boar sperm storage capacity of BTS and Androhep Plus: viability, motility, capacitation, and tyrosine phosphorylation. Theriogenology, 62: 874-886.

Even s o n D.P., L a r s on K.L., J o s t L.K. (2002). Sperm chromatin structure assay: its clinical use for detecting sperm DNA fragmentation in male infertility and comparisons with other techniques. J. Androl., 23: 25-43.

Gill a n L., Ev an s G., M a x w e 11 W.M. (2005). Flow cytometric evaluation of sperm parameters in relation to fertility potential. Theriogenology, 63: 445-457.

G o g o 1 P., S z c z ęśn i a k - F a bi a ń c z y k B. (2006). Effect of long-term storage on induced photon emission of boar spermatozoa. Czech J. Anim. Sci., 51: 61-65. 
G o g o 1 P., Wi erzchós - Hi l c zer A., C e g ł a M. (2007). Iron-induced luminescence as a method for assessing lipid peroxidation of frozen-thawed goat spermatozoa. Animal, 1: 844-848.

Gogol P., Szczęśniak-Fabiańczyk B., Wierzchoś-Hilczer A. (2009). The photon emission, ATP level and motility of boar spermatozoa during liquid storage. Reprod. Biol., 9: 39-49.

Górski K., Kondracki S., Wy sokińska A. (2017). Effects of season on semen parameters and relationships between selected semen characteristics in Hypor boars. Turk. J. Vet. Anim. Sci., 41: 563-569.

Ke nnedy B.W., Wilkins J.N. (1984). Boar, breed and environmental factors influencing semen characteristics of boars used in artificial insemination. Can. J. Anim. Sci., 64: 833-843.

Knecht D., Środoń S., D uziński K. (2014). The influence of boar breed and season on semen parameters. S. Afr. J. Anim. Sci., 44: 1-9.

Kn o x R.V. (2016). Artificial insemination in pigs today. Theriogenology, 85: 83-93.

Kondracki S., Wys okińska A., Banaszewska D., Woźniak E. (2004). The effect of breed variability on boar's semen characteristic (in Polish). Zesz. Nauk. AR Wrocław, Zootechnika, L, 488: 179-185.

K u m are s a n A., K a dirve 1 G., Buja rbaruah K.M., B ardoloi R.K., D a s A., Ku mar S., $\mathrm{N}$ a s k ar S. (2009). Preservation of boar semen at $18^{\circ} \mathrm{C}$ induces lipid peroxidation and apoptosis like changes in spermatozoa. Anim. Reprod. Sci., 110: 162-171.

P eň a Jr. S.T., S to ne F., Gu m m ow B., P a rker A.J., P a ris D.B.B. (2018). Tropical summer induces DNA fragmentation in boar spermatozoa: implications for evaluating seasonal infertility. Reprod. Fertil. Dev., 31: 590-601.

Pérez-Lla no B., En c is o M., García-Ca sa do P., S a la R., Go sálvez J. (2006). Sperm DNA fragmentation in boars is delayed or abolished by using sperm extenders. Theriogenology, 66: 2137-2143.

R e e d H.C.B. (1986). Influence of season on semen parameters and male fertility in the pig. In: Definition of the summer infertility problem in the pig, Seren S.E., Mattioli M. (eds.). Bologna, pp. 91-108.

Rodriguez A.L., Ann Van Soom A., Arsenakis I., Maes D. (2017). Boar management and semen handling factors affect the quality of boar extended semen. Porcine Health Manag., 3: 15.

S m i t a 1 J. (2009). Effects influencing boar semen. Anim. Reprod. Sci., 110: 335-346.

$\mathrm{S}$ m it a 1 J. (2010). Comparison of environmental variations in boar semen characteristics of six breeds and their crossbreds over an eight-year period. Res. Pig Breed., 4: 26-32.

S mital J., D e Sous a L.L., Mohs e n A. (2004). Differences among breeds and manifestation of heterosis in AI boar sperm output. Anim. Reprod. Sci., 80: 121-130.

S o n d e r m a n J.P., L u e b b e J.J. (2008). Semen production and fertility issues related to differences in genetic lines of boars. Theriogenology, 70: 1380-1383.

S zczęśniak-F a bi á́ c zyk B., B ochenek M., S morąg Z., Rys zka F. (2003). Effect of antioxidants added to boar semen extender on the semen survival time and sperm chromatin structure. Reprod. Biol., 3: 81-87.

S z c z ęś n i a k - F a b i án c z y k B., B o c he nek M., S m or ąg Z. (2007). Survival time and chromatin damage of boar semen stored in different diluents. Arch. Tierz. Dummestorf, 50 (Special Issue): 102-106.

$\mathrm{S} \mathrm{z} \mathrm{o} \mathrm{s} \mathrm{t} \mathrm{a} \mathrm{k} \mathrm{B.} \mathrm{(2003).} \mathrm{Influence} \mathrm{of} \mathrm{genotype,} \mathrm{age} \mathrm{of} \mathrm{boar} \mathrm{and} \mathrm{season} \mathrm{on} \mathrm{some} \mathrm{semen} \mathrm{characteristic} \mathrm{(in}$ Polish). Zesz. Nauk. Prz. Hod., 68: 147-155.

Trzcińska M., B ryła M. (2015). Apoptotic-like changes of boar spermatozoa in freezing media supplemented with different antioxidants. Pol. J. Vet. Sci., 18: 473-480.

Tr z c iń s k a M., B r yła M., S m o r ą g Z. (2008). Effect of liquid storage on membrane integrity and mitochondrial activity: a new diagnostic method of evaluating boar sperm quality. J. Anim. Feed Sci., 17: 372-380.

Ts a k mak id is I.A., K ha $\mathrm{l}$ i fa T.A.A., B o s cos C.M. (2012). Age-related changes in quality and fertility of porcine semen. Biol. Res., 45: 381-386.

Waberski D., S chapmann E., Henning H., Ries en beck A., B randt H. (2011). Sperm chromatin structural integrity in normospermic boars is not related to semen storage and fertility after routine AI. Theriogenology, 75: 337-345. 
Wy sokińska A., Kondrack i S., B an as zew sk a D., Z a j d a J. (2008). Features of boar ejaculate insemination depending on the breed and season (in Polish). Rocz. Nauk. PTZ, 4: 233-242.

Received: 20 IX 2018

Accepted: 16 V 2019 